\title{
Woodsiaceae endémicas del Perú
}

Blanca León ${ }^{1,2}$

${ }^{1}$ Museo de Historia Natural, Av. Arenales 1256, Aptdo. 14-0434, Lima 14, Perú

2 Plant Resources Center, University of Texas at Austin, Austin TX 78712 EE.UU

blanca.leon@mail.utexas.edu

\section{Resumen}

Los integrantes de esta familia fueron reconocidos en la flora del Perú en la Tribu Physematieae de las Dryopteridaceae (Tryon \& Stolze, 1991). La familia Woodsiaceae incluye cinco géneros y más de 40 especies (Tryon \& Stolze, 1991; Smith et al., 2005). Dos especies en un género son reconocidas como endémicas, las que ocupan la región del Bosque Húmedo Premontano, entre los 600 y 1600 m de altitud. Ninguna de las endémicas se conoce de poblaciones en un área protegida.

Palabras claves: Woodsiaceae, Perú, endemismo.

\section{Abstract}

Members of this family were recognized in the Peruvian flora in the Tribe Physematieae of the Dryopteridaceae (Tryon \& Stolze, 1991). The Woodsiaceae includes five genera and more than 40 species (Tryon \& Stolze, 1991; Smith et al., 2005). Two species in one genus are recognized as endemics; they occupy the region of the Humid Premontane Forest, between 600 and $1600 \mathrm{~m}$ elevation. No endemic species is found in a protected area.

Key words: Woodsiaceae, Peru, endemism.

\section{Diplazium flexuosum C. Presl}

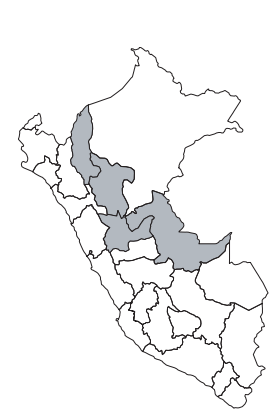

\section{VU, B1a}

Publicación: Tent. Pterid. 114. 1836.

Colección tipo: T. Haenke s.n.

Herbarios: K, PR.

Nombre común: Desconocido.

Registro departamental: AM, HU, SM, UC.

Regiones Ecológicas: BMHP; 1170$1600 \mathrm{~m}$.

SINANPE: Sin registro.

Herbarios peruanos: Ninguno.

Observaciones: Helecho terrestre, con hojas trepadoras, conocido de poblaciones dispersas y raras, en las cuencas del Utcubamba, Mayo, Huallaga y Ucayali. La mayor parte de las poblaciones, registradas en el siglo XIX e inicios del XX, provienen de la cuenca del Huallaga. Recientemente ha sido recolectada en la cuenca del Mayo, sobre rocas cálcicas.

\section{Diplazium paucijugum Stolze}

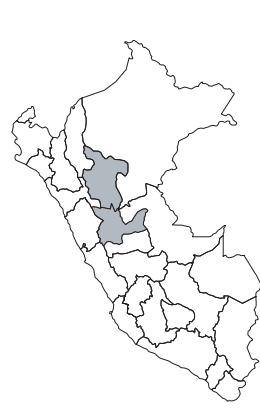

\section{EN, B1ab(iii)}

Publicación: Fieldiana Bot., n.s. 27: 84. 1991.

Colección tipo: R. Spruce 4339

Herbarios: $\mathrm{K}, \mathrm{P}$.

Nombre común: Desconocido,

Registro departamental: HU, SM. Regiones Ecológicas: BMHP, BHA; 600-1100 m.

SINANPE: Sin registro.

Herbarios peruanos: USM (1).

Observaciones: Helecho terrestre, conocido de tres localidades, en el norte y centro del país. Dos de esas localidades están ubicadas, en la cuenca del Mayo, cerca de Tarapoto, por lo que probablemente también se encuentre en el Parque Nacional Cordillera Azul. La población de Huánuco, se halla separada de las de San Martín por más de $350 \mathrm{~km}$, en línea recta. Amenazas a sus poblaciones podrían estar asociadas a la deforestación de los bosques montanos bajos. 